\title{
Relationship between the place of living and mortality in patients with advanced heart failure
}

Miguel-Angel Muñoz ${ }^{1,2,3^{*}}$ (D), Raquel Garcia ${ }^{1,2,3}$, Elena Navas ${ }^{2}$ Julio Duran ${ }^{4}$, José-Luis Del Val-Garcia ${ }^{1,2}$ and José-Maria Verdú-Rotellar ${ }^{1,2,5}$

\begin{abstract}
Background: Social and environmental factors in advanced heart failure (HF) patients may be crucial to cope with the end stages of the disease. This study analyzes health inequalities and mortality according to place of residence (rural vs urban) in HF patients at advanced stages of the disease.

Methods: Population-based cohort study including 1148 adult patients with HF attended in 279 primary care centers. Patients were followed for at least 1 year after reaching New York Heart Association IV functional class, between 2010 and 2014.

Data came from primary care electronic medical records. Cox regression models were applied to determine the hazard ratios (HR) of mortality.

Results: Mean age was 81.6 (SD 8.9) years, and 62\% were women. Patients in rural areas were older, particularly women aged $>74$ years $(p=0.036)$, and presented lower comorbidity. Mortality percentages were 59 and $51 \%$ among rural and urban patients, respectively $(p=0.030)$. Urban patients living in the most socio-economically deprived neighborhoods presented the highest rate of health service utilization, particularly with primary care nurses ( $p$-trend $<0.001$ ). Multivariate analyses confirmed that men (HR 1.60, 95\% confidence interval (Cl) 1.34-1.90), older patients ( $\mathrm{HR} 1.05,95 \% \mathrm{Cl}$ 1.04-1.06), Charlson comorbidity index (HR 1.16, 95\% Cl 1.11-1.22), and residing in rural areas (HR 1.35, 95\% Cl 1.09 to 1.67) was associated with higher mortality risk.
\end{abstract}

Conclusions: Living in rural areas determines an increased risk of mortality in patients at final stages of heart failure.

Keywords: Advanced heart failure, Rural health, Community healthcare, Health inequalities

\section{Background}

According to data published by the World Bank, the percentage of rural populations fluctuates from 19 to $59 \%$ depending on the degree of development of the countries in question [1]. In spite of these figures, however, differences

\footnotetext{
* Correspondence: mamunoz.bcn.ics@gencat.cat

${ }^{1}$ Institut Català de la Salut, Barcelona, Spain

${ }^{2}$ Fundació Institut Universitari per a la recerca a l'Atenció Primària de Salut Jordi Gol i Gurina (IDIAPJGol), Carrer Sardenya 375, Entresol, 08025 Barcelona, Spain

Full list of author information is available at the end of the article
}

in health and disease patterns between rural and urban areas have not been widely studied [2].

Evidence concerning inequalities in health and mortality between rural and urban settings, has reported conflicting results with respect to the source and characteristics of the population [3, 4].

With respect to cardiovascular diseases, coronary heart disease mortality has been observed to be more prevalent in rural areas [5], and similar results have been published for heart failure (HF) although only regarding men [6].

(c) The Author(s). 2020 Open Access This article is licensed under a Creative Commons Attribution 4.0 International License, which permits use, sharing, adaptation, distribution and reproduction in any medium or format, as long as you give appropriate credit to the original author(s) and the source, provide a link to the Creative Commons licence, and indicate if changes were made. The images or other third party material in this article are included in the article's Creative Commons licence, unless indicated otherwise in a credit line to the material. If material is not included in the article's Creative Commons licence and your intended use is not permitted by statutory regulation or exceeds the permitted use, you will need to obtain permission directly from the copyright holder. To view a copy of this licence, visit http://creativecommons.org/licenses/by/4.0/ The Creative Commons Public Domain Dedication waiver (http://creativecommons.org/publicdomain/zero/1.0/) applies to the data made available in this article, unless otherwise stated in a credit line to the data. 
Whilst the HF incidence rate has declined in recent years, its prevalence has increased, suggesting that survival over time is longer, probably due to better care and treatment [7]. Nevertheless, this improvement in survival is modest [8], and research in HF is considered one of the most important priorities [9]. Patients classified as New York Heart Association (NYHA) functional class III/IV present almost four-fold greater rates of mortality, and up to $58.3 \%$ of NYHA functional class IV dies after a five-year follow-up $[10,11]$. However, due to its irregular evolution, HF is not usually considered a terminal disease, whilst at advanced stages it could be compared to malignant neoplasms [12].

Although many predictors of mortality among HF patients have been well identified [13], social and environmental determinants are not usually included in predictive models, particularly in patients at terminal stages of the disease. Some studies have shown worse prognoses regarding socio-economic position [14], social risk [15], health literacy [16] and urban areas of residence [17].

Even though gaps in the availability of general palliative care in rural areas have been reported [18], information about the differences in the lifetime of HF patients or health services utilization depending on their residence and socio economic level is scarce.

This study was aimed at analyzing health inequalities and mortality according to place of residence (rural vs urban) in HF patients at advanced stages of the disease (NYHA functional class IV) attended in the community by analyzing real world data.

\section{Methods}

We followed a population-based cohort of adult patients presenting the most advanced stages of heart failure (NYHA functional class IV) between January 1st, 2010, and December 31st, 2014.

The inclusion date was taken to be when patients were first registered as having NYHA functional class IV in their primary healthcare electronic medical records during the study period. NYHA functional class IV was considered when patients diagnosed from HF were unable to carry on any physical activity without symptoms of HF, or symptoms of HF at rest [19]. The whole cohort was followed-up for at least 1 year from the inclusion date or until a fatal occurrence took place during the study period.

Information was collected from the primary care electronic medical records, through the Information System for the Development of Research in Primary Care (SIDI AP). This database contains data from 5.8 million individuals attended in 279 primary healthcare centers which attend $80 \%$ of the whole population of Catalonia (north-east Spain), and it has already been validated for use in cardiovascular research [20].
The database incorporates both administrative and clinical data which are encrypted to guarantee the confidentiality and anonymization of the information gathered for research purposes and provides data about diagnoses, clinical characteristics, comorbidity, laboratory and diagnostic tests, social and demographic variables, and performance in activities of daily living, tests to evaluate functional physical and mental status, drug prescriptions, and primary health care service utilization. Information regarding the patients' vital status is also included and comes from the Central Insurance Register (RCA) (ie, if patient is death or alive).

Patients with HF were identified using the International Classification of Diseases, Tenth Revision (ICD 10), claim code I50.

The ICD 10 codes selected to register comorbidities were: diabetes (E10-E14), hypertension (I10-I15), coronary heart disease (I20-I25), stroke (I63-I65), atrial fibrillation (I48), chronic kidney disease (N18), chronic lower respiratory diseases (J40-J44), and cancer (C00-C97).

Clinical variables, laboratory analyses, and tests assessing functional were obtained from the patient's consultation closest to the inclusion date, and missing values were imputed.

The Barthel index, which has proved helpful in assessing the functional status of a patient [21], and the Charlson index, used to predict ten-year mortality and healthcare resource utilization in patients with a range of comorbid conditions [22] were regularly collected during the nurses' consultations.

To determine socio-economic status among the urban patients we employed the MEDEA Index which is an aggregated socioeconomic deprivation model which classify the population living in small geographical areas, according to the percentage of unemployment, manual and temporary workers, and individuals with insufficient education (less than primary school). The lowest quintile (Urban areas 1) represents individuals with the most favorable socio-economic position, and the upper one the worst (Urban areas 1). The unit of aggregation was the census tracts, which is the smallest territorial unit for which population data are available in our country. This index has been proven valid for urban areas although in rural ones it does not discriminate accurately [23].

Family networks, as well as living conditions, were assessed through an interview by a social workers or nurses using the Gijon social-family scale, which includes questions about housing conditions, family and social relationships and income [24].

Family network was explored by the following items: Living with relatives (physically independent), living with relatives (physically dependent), living with a partner, living alone (offspring close to their home), and living alone (offspring far from their home). We grouped the 
last two variables and classified family network as living alone or not.

Regarding housing conditions, we considered them inadequate when the house had structural barriers, humidity or incomplete facilities, no elevator or telephone or patients were living in a slum.

Health service utilization was computed as the number of consultations made with the family physician, primary care nurse, or specific primary care emergency services.

Rural residence was defined when patients lived in an area with less than 10,000 inhabitants, or the density of population was lower than 150 inhabit $/ \mathrm{km} 2$, according to the Catalan Healthcare Administration classification [25].

The prescription of angiotensin converting enzyme inhibitors, angiotensin II receptor blockers, beta blockers, mineral corticoid antagonists, and loop diuretics was also collected.

The primary outcome was all-cause mortality occurring during the follow-up.

\section{Statistical analysis}

Continuous variables were described by means, Standard deviation, and median, and percentages were used to describe categorical variables.

Variables included in the analyses were: sociodemographic, clinical and laboratory test data, comorbidity, consultations made to primary healthcare professionals, activities of daily living, presence of family networks, housing conditions and medication related to HF.

Living in urban or rural residence was the main independent variable and global mortality was the end point of the study.

The Anova test was performed to compare the number of visits according to the different levels of MEDEA deprivation index as a categorical variable.

Characteristics related to mortality and differences between urban and rural patients were first compared using chi-square test or Student $t$ test.

Odds ratios were estimated by logistic regression models to evaluate the relationship between urban and rural residence and to evaluate the association between these characteristics, the place of residence and mortality.

Multiple imputation models were performed to manage the missing data by using the "Mice" and "VIM" $\mathrm{R}$ packages. The "mice" function is based on the conditional specification, where each incomplete variable is imputed with a separate model. A total of 50 imputations were generated and the final data were obtained with the "complete" function that generates a complete data set that combines the observed and imputed values.

Cox multivariate logistic regression was used to analyse the characteristics related to mortality and covariates included in the model. Socio demographic variables and those statistically significant (at level $p<0.01$ ) in the bivariate analyses (sex, age, Charlson Index, place of residence, diabetes mellitus, and number of visits to primary care urgencies) were included in the final model.

Statistical analysis was conducted using R Software for Windows version 3.6.1, Vienna, Austria.

\section{Results \\ Descriptive findings}

We analyzed data from 1148 HF patients in NYHA functional class IV. Mean age was 81.6 (SD 8.9), 95\% of patients were older than 64 years, and $61 \%$ were women. Most of the population lived in urban areas $(N=972)$ and more than $69 \%$ were older than 74 years $(N=793)$. Among the total number of patients included, $68 \%$ presented high comorbidity according to the Charlson index (score $>=3$ ), and daily living activities were moderately to severely affected (Barthel Index <60) in 56\%.

The most frequently associated comorbidities were hypertension (79\%), atrial fibrillation (47\%), diabetes (42\%), and coronary heart disease (34\%). Cardiovascular comorbidity (coronary heart disease, atrial fibrillation, and stroke) was present in $69 \%$ of the patients, and $22 \%$ presented two or more of these conditions.

Regarding the number of chronic conditions included in the analyses, the median was 3 (percentile 25-75, 24), and $62 \%$ of HF patients had simultaneously three or more comorbidities.

Beta-blockers, angiotensin converting enzyme inhibitors/angiotensin II receptor blockers, and mineral corticoid antagonists were prescribed in 45,66 , and $26 \%$ of patients, respectively. A combination of the three medications was present in $10 \%$, whilst loop diuretics were prescribed in $88 \%$.

During the period of the study, patients consulted their family physician on average 22 occasions, 20 with their primary care nurse, and on three occasions the primary healthcare emergency centers.

\section{Differences between urban and rural patients}

Mean follow-up until the end of the study, or the occurrence of a fatal event, was 16 months (SD 12.4) for urban and 14.5 months (SD 10.9) for rural patients, respectively.

Although rural patients were, on average, 2 years older, they presented lower comorbidity (Charlson index). In spite of not being statistically significant, the urban cohort tended to live more commonly alone.

No differences in cardiovascular comorbidity, clinical variables, performance in activities of daily living, or HF medication were reported between rural and urban patients.

Table 1 describes how in analyses stratified by gender there were no outstanding differences regarding place of residence in any of the variables, with the exception of age (older women in rural areas) and the higher percentage of women living alone in the cities. 
Table 1 Characteristics of patients with heart failure at New York Heart Association IV functional class, according to their place of residence

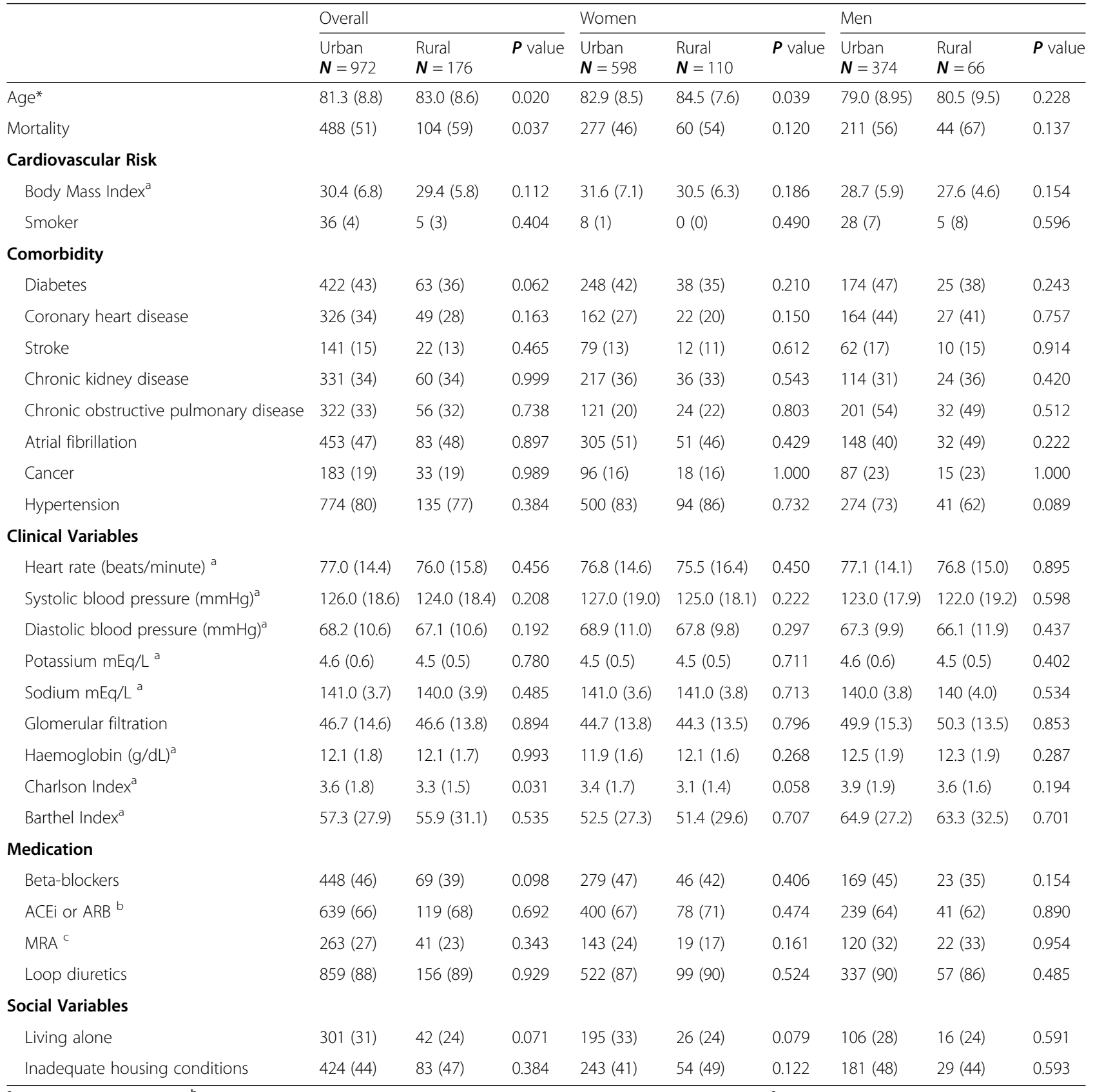

${ }^{\mathrm{a}}$ Mean (Standard deviation); ${ }^{\mathrm{b}}$ ACEi angiotensin converting enzyme inhibitors and ARB Angiotensin II receptor blockers), ${ }^{\mathrm{c}}$ MRA mineralocorticoid receptor antagonists

We compared primary healthcare service utilization by HF patients, according to place of residence and socioeconomic deprivation it was observed that those in the most socio-economically deprived urban areas tended to use more frequently primary care emergency services than the other urban individuals, and even three more times compared to rural ones. Regarding consultations with the family physician and primary healthcare nurses, patients in the most deprived urban areas were the greatest users of the former and this higher utilization was statistically significant in the case of the later (Fig. 1).

\section{Overall mortality}

Among the 592 patients (52\%) who died during the period of the study, 488 (82\%) lived in urban and 104 (18\%) in rural areas, respectively. Analyzing the number of fatal events during follow-up, the mean rate of survival from study inclusion was 10.6 (SD 9.9) and 9.8 (SD 9.8) months, for the urban and rural cohorts, respectively. 

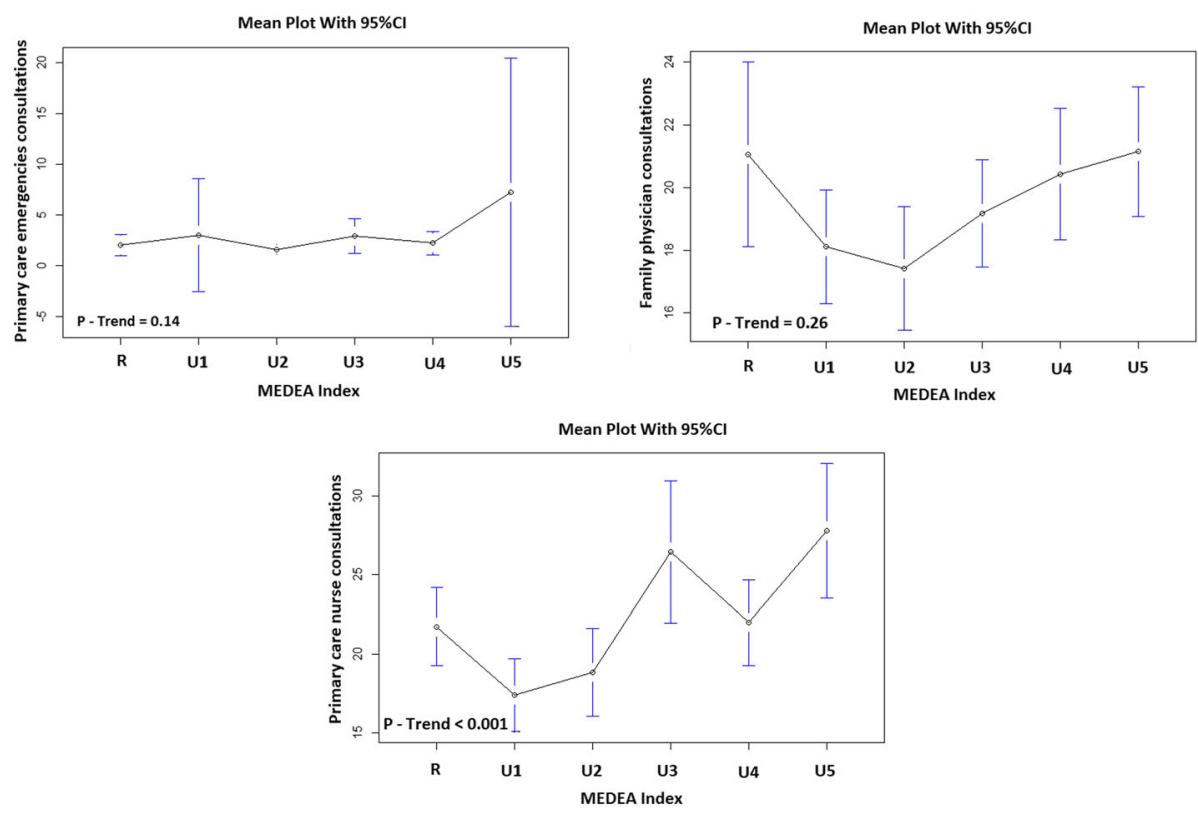

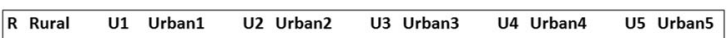

Fig. 1 Primary healthcare services utilization by urban patients with heart failure at New York heart Association (NYHA) functional class IV according to the place of residence ( $U$ 1: urban less socioeconomically deprived area to $\cup$ 5: urban most socioeconomically deprived area)

Older age, Charlson comorbidity index, chronic kidney disease, higher potassium levels, and cancer, were related with a higher risk of dying.

In contrast, greater body mass index, blood pressure, glomerular filtration, Barthel index, and hemoglobin were protective with respect to mortality risk (Table 2).

When analyzing sociodemographic variables related to mortality we found that being men, older, living in rural areas and having unfavorable housing conditions (structural barriers and lack of facilities) were related to higher probability of dying, but no significant differences were found among urban patients regarding the area where they lived.

Table 3 shows the differences in mortality according to the fact of living in urban and rural areas. Older age, chronic kidney disease, lower levels of blood pressure, lower levels of haemoglobine and lower body mass index were more commonly related to mortality, regardless the place of residence. We observed that in patients living in rural areas the prevalence of stroke among those patients who died was higher, whilst in urban patients mortality was higher in those with higher prevalence of cancer, lower Barthel Index and worse levels of creatinine.

\section{Multivariate analyses}

Cox multivariate regression model, adjusted by the variables significantly associated both with the mortality and the place of living, confirmed that being men, older, having higher comorbidity, and living in rural areas were associated with higher risk of mortality (Fig. 2). The excess of mortality risk for men was $60 \%$ whilst for patients living in rural areas it was 35\% (HR 1.35, 95\% CI 1.09 to 1.67$)$.

\section{Discussion}

In our study, based on a community cohort of HF patients at the most advanced stages of the disease, we observed that mortality was 35\% higher in those residing in rural setting. Being men, aged, and presenting higher comorbidity were also found to be related to a greater risk of dying. We found an inverse gradient in primary healthcare resources utilization regarding socioeconomic deprivation among urban patients, those residing in the most deprived socio-economic areas had the highest health services utilization.

Compared to the rest of Europe, the population density in the study region is among one of the highest, the distribution is, however, irregular with more than $40 \%$ of the inhabitants concentrated in the metropolitan area of Barcelona. Although a number of small hospitals are distributed across the territory, most tertiary hospitals are located in this large metropolitan area which can limit accessibility of rural patients to highly specialized care.

With respect to place of residence, we did not observe differences in clinical characteristics or HF medication prescribed. Although rural women were slightly older, urban patients presented higher comorbidity and reported more social isolation. This last finding concurs 
Table 2 Characteristics related to the overall mortality of patients with heart failure at New York heart Association IV functional class, according to gender

\begin{tabular}{|c|c|c|c|c|c|c|c|c|c|}
\hline & \multicolumn{3}{|l|}{ Overall } & \multicolumn{3}{|l|}{ Women } & \multicolumn{3}{|l|}{ Men } \\
\hline & $\begin{array}{l}\text { Alive } \\
\boldsymbol{N}=556\end{array}$ & $\begin{array}{l}\text { Dead } \\
\boldsymbol{N}=592\end{array}$ & $\boldsymbol{P}$ value & $\begin{array}{l}\text { Alive } \\
\boldsymbol{N}=371\end{array}$ & $\begin{array}{l}\text { Dead } \\
\boldsymbol{N}=337\end{array}$ & $\boldsymbol{P}$ value & $\begin{array}{l}\text { Alive } \\
\boldsymbol{N}=185\end{array}$ & $\begin{array}{l}\text { Dead } \\
\boldsymbol{N}=255\end{array}$ & $\boldsymbol{P}$ value \\
\hline Age & $79.7(9.3)$ & $83.3(8.0)$ & $<0.001$ & $81.4(8.6)$ & $85.0(7.7)$ & $<0.001$ & $76.5(9.9)$ & $81.2(7.7)$ & $<0.001$ \\
\hline Body Mass Index & $31.5(6.7)$ & $28.9(6.4)$ & $<0.001$ & $32.4(6.8)$ & $30.1(7.0)$ & $<0.001$ & $30.0(6.2)$ & $27.5(5.2)$ & $<0.001$ \\
\hline Smoker & $22(4)$ & $19(3)$ & 0.698 & $7(2)$ & $1(0)$ & 0.112 & $15(8)$ & $18(7)$ & 0.009 \\
\hline \multicolumn{10}{|l|}{ Comorbidity } \\
\hline Diabetes & $234(42)$ & $251(42)$ & 0.971 & $154(41)$ & $132(39)$ & 0.577 & $80(43)$ & $119(47)$ & 0.538 \\
\hline Coronary heart disease & $178(32)$ & $197(33)$ & 0.782 & $100(27)$ & $84(25)$ & 0.597 & $78(42)$ & $113(44)$ & 0.725 \\
\hline Stroke & $78(14)$ & $85(14)$ & 0.854 & $50(14)$ & $41(12)$ & 0.683 & $28(15)$ & $44(17)$ & 0.644 \\
\hline Chronic kidney disease & $162(29)$ & 229 (39) & $<0.001$ & $119(32)$ & $134(40)$ & 0.040 & $43(23)$ & $95(37)$ & 0.003 \\
\hline Chronic obstructive pulmonary disease & $170(31)$ & $208(35)$ & 0.089 & $76(21)$ & $69(21)$ & 1.000 & $94(51)$ & $139(55)$ & 0.502 \\
\hline Atrial fibrillation & $254(46)$ & $282(48)$ & 0.707 & $184(50)$ & $172(51)$ & 0.758 & $70(38)$ & $110(43)$ & 0.309 \\
\hline Cancer & $81(15)$ & $135(23)$ & $<0.001$ & $54(15)$ & $60(18)$ & 0.284 & $27(15)$ & $75(29)$ & $<0.001$ \\
\hline Hypertension & $449(81)$ & $460(77)$ & 0.218 & $313(84)$ & $281(83)$ & 0.800 & $136(74)$ & $179(70)$ & 0.513 \\
\hline \multicolumn{10}{|l|}{ Clinical Variables } \\
\hline Heart Rate (beats/minute) ${ }^{a}$ & $76.6(15.2)$ & $76.8(14.0)$ & 0.735 & $76.7(15.4)$ & $76.5(14.3)$ & 0.798 & $76.4(14.9)$ & $77.4(13.7)$ & 0.487 \\
\hline Systolic blood pressure $(\mathrm{mmHg})^{a}$ & $127.7(18.4)$ & $123.3(18.5)$ & $<0.001$ & $129(18.3)$ & $125(19.2)$ & 0.007 & $126(18.4)$ & $121(17.5)$ & 0.009 \\
\hline Diastolic blood pressure $(\mathrm{mmHg})^{a}$ & $69.5(10.7)$ & $66.7(10.3)$ & $<0.001$ & $70.2(11.1)$ & $67.1(10.3)$ & $<0.001$ & $68.2(9.8)$ & $66.3(10.4)$ & 0.051 \\
\hline Potassium mEq/L ${ }^{a}$ & $4.5(0.5)$ & $4.6(0.6)$ & 0.033 & $4.4(0.5)$ & $4.5(0.5)$ & 0.133 & $4.5(0.6)$ & $4.6(0.6)$ & 0.370 \\
\hline Sodium mEq/L ${ }^{a}$ & $140.8(3.5)$ & $140.5(3.9)$ & 0.060 & $141(3.4)$ & $141(3.7)$ & 0.351 & $141(3.5)$ & $140(3.9)$ & 0.309 \\
\hline Glomerular filtration & $1.2(0.6)$ & $1.4(0.8)$ & $<0.001$ & $1.1(0.4)$ & $1.3(0.5)$ & $<0.001$ & $1.3(0.8)$ & $1.5(1.0)$ & 0.007 \\
\hline Hemoglobin $(\mathrm{g} / \mathrm{dL})^{\mathrm{a}}$ & $12.3(1.7)$ & $11.9(1.8)$ & $<0.001$ & $12.2(1.5)$ & $11.7(1.7)$ & $<0.001$ & $12.8(1.9)$ & $12.3(1.9)$ & 0.009 \\
\hline Barthel Index ${ }^{a}$ & $59.8(27.8)$ & $54.4(28.6)$ & $<0.001$ & $55.9(27.2)$ & $48.5(27.6)$ & $<0.001$ & $67.8(27.5)$ & $62.4(28.2)$ & 0.043 \\
\hline Charlson Index ${ }^{a}$ & $3.2(1.6)$ & $3.8(1.8)$ & $<0.001$ & $3.2(1.5)$ & $3.5(1.6)$ & 0.024 & $3.4(1.6)$ & $4.2(1.9)$ & $<0.001$ \\
\hline \multicolumn{10}{|l|}{ Medication } \\
\hline Beta-blockers & $271(49)$ & $246(42)$ & 0.011 & $182(49)$ & $143(42)$ & 0.091 & $89(48)$ & $103(40)$ & 0.130 \\
\hline ACEi or ARB ${ }^{b}$ & $397(71)$ & $361(61)$ & $<0.001$ & $262(71)$ & $216(64)$ & 0.077 & $135(73)$ & $145(56)$ & 0.001 \\
\hline $\mathrm{MRA}^{\mathrm{c}}$ & $145(26)$ & $159(27)$ & 0.883 & $83(22)$ & $79(23)$ & 0.803 & $62(33)$ & $80(31)$ & 0.711 \\
\hline Loop diuretics & $479(86)$ & $536(91)$ & 0.083 & $315(85)$ & $306(91)$ & 0.023 & $164(89)$ & $230(90)$ & 0.714 \\
\hline \multicolumn{10}{|l|}{ Social Variables } \\
\hline Living alone & $164(29)$ & $179(30)$ & 0.988 & $121(33)$ & $100(30)$ & 0.446 & $43(23)$ & $79(31)$ & 0.093 \\
\hline Inadequate housing conditions & $220(40)$ & $287(48)$ & 0.002 & $131(35)$ & $166(49)$ & $<0.001$ & $89(48)$ & $121(47)$ & 0.968 \\
\hline
\end{tabular}

with a previous study reporting that in a rural environment it is easier to rely on family members [26].

Although the bivariate analyses found statistical differences in the characteristics associated with mortality depending on rural or urban setting, these differences were not clinically relevant.

We found a considerable number of consultations, particularly with primary care nurses, among the urban patients living in the most deprived areas. In this regard, it has already been reported that low income and other psycho-social disadvantages imply greater healthcare resource utilization [27].

\section{Mortality}

The higher mortality described for men, older HF patients, and in those with decreased body mass index, chronic kidney disease, and lower blood pressure levels, concurs with previous studies, particularly in the advanced stages of the disease [28-30]. Moreover, higher mortality in rural patients is in agreement with a previous study [6].

It has been hypothesized that populations residing in urban areas have better health due to easier accessibility to health services, in addition to better jobs and income [3]. 
Table 3 Characteristics related to the mortality of patients with heart failure at New York Heart Association IV functional class according to their place of residence

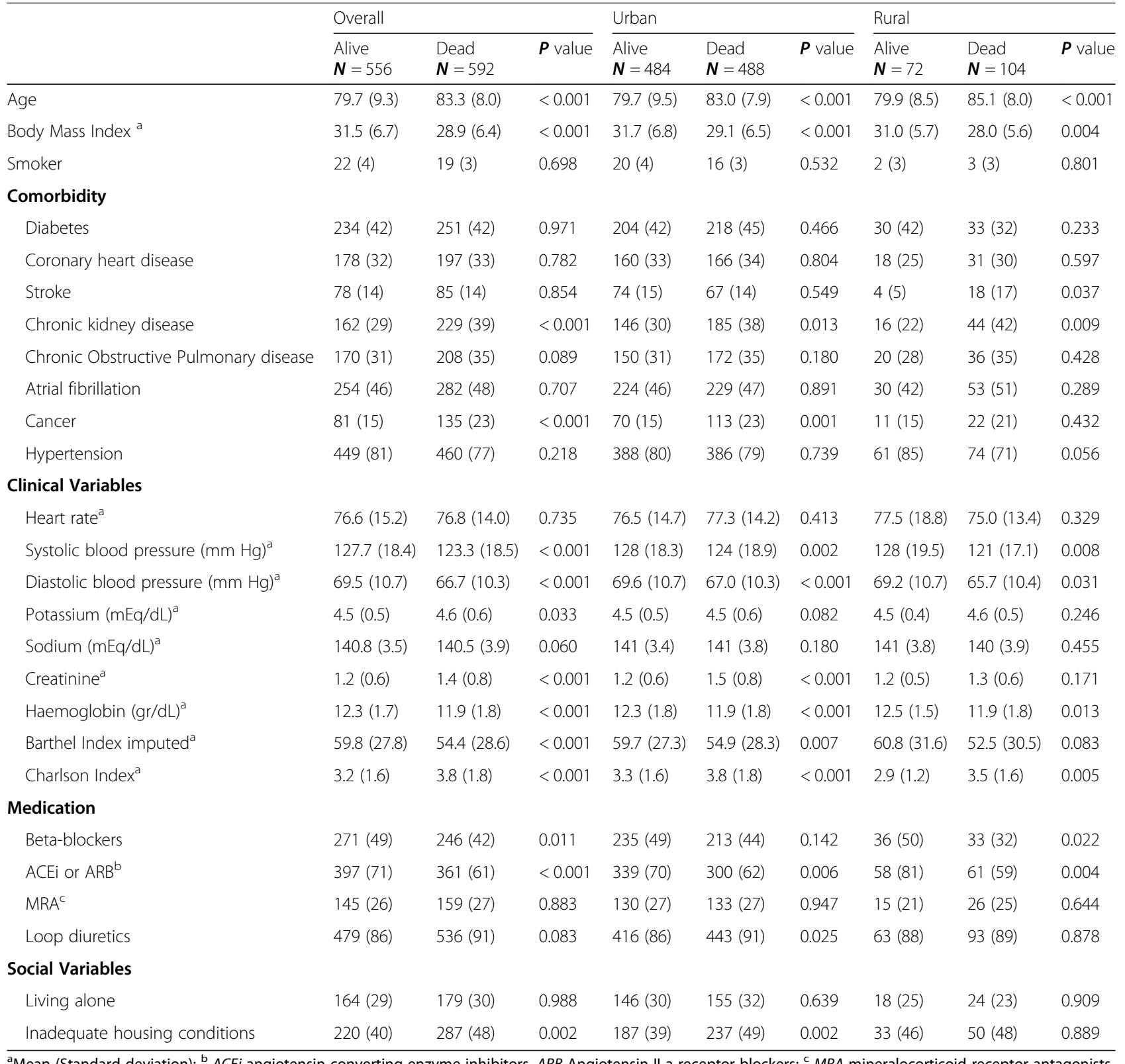

Regarding cardiovascular diseases, inequalities in rural patients have been reported with respect to access to treatment, such as percutaneous coronary interventions, which require a longer travelling distance [31].

Another possible factor contributing higher mortality among rural HF patients in our sample could be the differences reported in the use of health services, although we cannot affirm that highest primary care services utilization by urban patients determines longer survival.

There is a widespread network of primary healthcare out-of-hours centers, nevertheless, its distribution and characteristics vary. These centers are more complete in large cities, offering services such as radiology and laboratory tests, which may improve the diagnosis and treatment of complications whilst in the rural areas more complex assistance needs to be provided in small hospitals.

Many rural patients lack daily access to their family doctors which can lead to delay in the treatment of decompensations. Urban primary healthcare centers are opened between 8 am and 8 pm every day, whilst many rural villages do not have general practitioner accessible all days, and population must travel long distances to be attended, especially in out of hours. 


\begin{tabular}{|c|c|c|c|c|c|}
\hline Variable & & $\begin{array}{c}\text { Mortality } \\
\text { (Number of deaths) }\end{array}$ & & $\begin{array}{l}\text { Hazard Ratio } \\
95 \% \text { Confidence Interval }\end{array}$ & P.Value \\
\hline \multirow[t]{2}{*}{ Sex } & Women & 337 & $\square$ & Reference & \\
\hline & Men & 255 & $\longmapsto$ & $1.60(1.35,1.90)$ & $<0.001$ \\
\hline Age (Years) & & & - & $1.05(1.04,1.06)$ & $<0.001$ \\
\hline \multicolumn{2}{|l|}{ Charlson Index } & & $=$ & $1.15(1.09,1.21)$ & $<0.001$ \\
\hline Place of living & Urban & 488 & 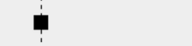 & Reference & \\
\hline & Rural & 104 & $\longmapsto \square$ & $1.35(1.09,1.67)$ & 0.006 \\
\hline \multirow[t]{2}{*}{ Diabetes } & No & 341 & $\boldsymbol{\square}$ & Reference & \\
\hline & Yes & 251 & $\longrightarrow$ & $0.98(0.82,1.18)$ & 0.844 \\
\hline
\end{tabular}

Fig. 2 Hazard ratio and 95\% confidence interval for variables predicting mortality adjusted by sex, age, Charlson comorbidity index, diabetes mellitus and place of living

Other factors might be involved in explaining in these differences such as the decision to die at home allows patients to maintain control over their lives. The approach to the end of life could be culturally different in a rural setting compared to an urban one. A recent systematic review oriented to analyse the socio-economic factors determining the place of death found that dying at home was associated with living in rural areas but, potential causes remain unsolved [32]. Mean survival time among patients who died in our study was slightly higher among the urban ones. Nevertheless, considering the considerable limitations such patients undergo in their daily activities, it may be questioned whether this increased survival time is cost effective in terms of quality of life.

Evidence regarding socioeconomic deprivation among urban residents is controversial. Hawkins et al., employing a geographical composite deprivation index similar to ours, and analyzing data from 2000 to 2007, did not describe differences regarding outcomes in HF patients [33]. In a more recent article, Witte et al., using the same deprivation index as Hawkins, reported that socioeconomic deprivation was linked to an increased risk of death in HF patients, but only as a consequence of noncardiovascular causes [34]. In addition, a study performed with the same population in our country showed a protective, although not significant, effect regarding mortality in the most deprived urban patients [17].

The National Health Service in our country provides universal healthcare, which may reduce social inequalities in health by facilitating access to primary care, prescriptions and hospitals to populations lacking economic resources, but the distribution of healthcare premises in rural and remote areas is conditioned by geographical limitations.

Nevertheless, future research will be needed to explain why, with no differences in either cardiovascular comorbidities or treatment, rural HF patients had the highest mortality rates.

\section{Strengths and limitations}

Although different approaches have been employed to define rurality, our definition concurs with others used in similar articles. Nevertheless, due to data limitations, we could not fully discriminate the analyses between patients living in the most isolated areas from the other rural ones to ascertain whether differences in accessibility related to mortality are proportional to distance and frequency of healthcare service provision. The deprivation index used to study urban socioeconomic differences assumes homogeneity among the population living in the same geographical area, but may imply an ecological fallacy because it is possible to find both poor and affluent individuals in the same areas, sometimes divided by only one street. Moreover, we lack information in order to discriminate the presence of socio-economic differences within rural populations and thus considered them homogeneous in terms of social status.

Since administrative databases are used for clinical purposes can lead to missing data. In the case of HF some variables such as ejection fraction are not always available to have proper diagnoses according to guidelines [35]. Nevertheless in our study this fact is not relevant because all patients were at final stages of the disease. Regarding other possible missing values we performed multiple imputation models to minimize such an effect.

It would be advantageous to possess data regarding quality of life in order to analyze differences among rural and urban patients.

The results of our study are potentially valid for areas of the rest of our country with similar characteristics, concentrating population in large cities. Nevertheless, in 
Spain and in Europe there are many areas where the rural depopulation is remarkable, and the accessibility to healthcare services could be different.

Since our results are based on information coming from more than $80 \%$ of the Catalan population, it is expected to think that they could be extrapolated to the rest.

Prospective studies would be needed, not just to observe the presence of differences depending on the place of living but oriented towards specifically analyse their causes, to be more precise in measuring the differences in the accessibility, the characteristics of patients, exploring their perceptions and needs as well as their beliefs and preferences regarding the treatment received at the end of life.

To our knowledge, evidence about differences between rural and urban heart failure patients, particularly at advances stages of the disease is scarce. This article specifically analyses evidence from electronic health records from elderly HF patients at advanced stages of the disease through a large database.

\section{Conclusions}

Mortality in elderly patients with heart failure at the final stage of HF is higher among those living in rural setting. Accessibility and inequalities in the healthcare provided with respect to the place of residence may contribute to such differences. The increased healthcare services utilization by urban patients living in most socioeconomic deprived areas is not followed by a reduction in mortality.

Health policies should face with social and geographical inequalities, to ensure that most part of population have similar access to healthcare provision, especially to primary care services, which are essential in improving health and reducing mortality.

\section{Abbreviations}

HF: Heart failure; NYHA: New York Heart Association; HR: Hazard ratios; Cl: Confidence interval; RCA: Central Insurance Register; SIDIAP: Information System for the Development of Research in Primary Care.

\section{Acknowledgements}

We thank to the Information System for the Development of Research in Primary Care (SIDIAP) professionals their support with data collection.

\section{Authors' contributions \\ MAM, RG, JLV, EN, JD, and JMVR participated in the interpretation of results, the elaboration and revision of the drafts of the manuscript and in the approval of the final version. EN participated in the data management, analysis and elaboration of the last draft and the approval of the final version. All the authors gave final approval of the version to be published.}

\section{Funding}

This study has been granted by the Primary Healthcare University Research Institute IDIAP-Jordi Gol. By this grant, the Institute assumed the costs originated to the SIDIAP database, related to the elaboration and data management to develop this study.

\section{Availability of data and materials}

The datasets generated and/or analysed during the current study are not publicly available due to the restrictions by the data owner (IDIAP Research Institute), but could be available from the corresponding author on reasonable request.

\section{Ethics approval and consent to participate}

The study protocol was approved by the Primary Healthcare University Research Institute IDIAP- Jordi Gol ethics committee (reference number: P13/ 052). Confidentiality of data was guaranteed in all the process of the study, and data available for research purpose was anonymous. Since the data obtained underwent a double process of anonymization, no interventions were made and the research team had not access to the patient information, ethics committee considered not necessary the patient informed consent either verbal nor written. To obtain the access to the database an external scientific committee from IDIAP Jordi Gol assessed and approved the quality and appropriateness of the study protocol, before its submission to the ethics committee. We had permission from our Research Institute (IDIAP Jordi Gol) to accede to the database and publish this manuscript.

\section{Consent for publication}

Not applicable.

\section{Competing interests}

The authors declare that they have no competing interests.

\section{Author details}

${ }^{1}$ Institut Català de la Salut, Barcelona, Spain. ${ }^{2}$ Fundació Institut Universitari per a la recerca a l'Atenció Primària de Salut Jordi Gol i Gurina (IDIAPJGol), Carrer Sardenya 375, Entresol, 08025 Barcelona, Spain. ${ }^{3}$ Department of Pediatrics, Obstetrics and Gynecology and Preventive Medicine, Universitat Autònoma de Barcelona, Bellaterra, Spain. ${ }^{4}$ Clínica Sant Antoni. Institut Mèdic i de Rehabilitació, Barcelona, Spain. ${ }^{5}$ Department of Medicine, Universitat Autònoma de Barcelona, Bellaterra, Spain.

Received: 30 January 2020 Accepted: 7 July 2020

Published online: 14 July 2020

\section{References}

1. United Nations Population Division's World Urbanization Prospects: 2018 Revision. https://data.worldbank.org/indicator/SP.RUR.TOTL.ZS. Accessed 28 Aug 2019.

2. Moreno-Lostao A, Guerras JM, Lostao L, de la Fuente L, Martínez D, Rodríguez-Artalejo F, et al. Cardiovascular mortality and risk behaviours by degree of urbanization before, during and after the economic crisis in Spain. BMC Public Health. 2019;19(1):1109.

3. House JS, Lepkowski JM, Williams DR, Mero RP, Lantz PM, Robert SA, et al. Excess mortality among urban residents: how much, for whom, and why? Am J Public Health. 2000;90(12):1898-904.

4. Eberhardt MS, Pamuk ER. The importance of place of residence: examining health in rural and non rural areas. Am J Public Health. 2004:94(10):1682-6.

5. Kulshreshtha A, Goyal A, Dabhadkar K, Veledar E, Vaccario V. Urban-rural differences in coronary heart disease mortality in United States: 1999-2009. Public Health Rep. 2014;129:19-29.

6. Gamble JM, Eurich DT, Ezekowitz JA, Kaul P, Quan H, McAlister FA. Patterns of care and outcomes differ for urban versus rural patients with newly diagnosed heart failure, even in a universal healthcare system. Circ Heart Fail. 2011:4(3):317-23.

7. Heidenreich PA, Albert NM, Allen LA, Bluemke DA, Butler J, Fonarow GC, et al. Forecasting the impact of heart failure in the United States: a policy statement from the American Heart Association. Circ Heart Fail. 2013;6:60619.

8. Taylor CJ, Ordóñez-Mena JM, Roalfe AK, Lay-Flurrie S, Jones NR, Marshall T, et al. Trends in survival after a diagnosis of heart failure in the United Kingdom 2000-2017: population based cohort study. BMJ. 2019;364:1223.

9. Drake C, Wald HL, Eber LB, Trojanowski Jl, Nearing KA, Boxer RS. Research priorities in post-acute and long-term care: results of a stakeholder needs assessment. J Am Med Dir Assoc. 2019;20(7):911-5.

10. Muntwyler J, Abetel G, Gruner C, Follath F. One-year mortality among unselected outpatients with heart failure. Eur Heart J. 2002;23(23):1861-6. 
11. Ahmed A, Aronow WS, Fleg JL. Higher New York heart association classes and increased mortality and hospitalization in patients with heart failure and preserved left ventricular function. Am Heart J. 2006;151(2):444-50.

12. Jaarsma $T$, Beattie JM, Ryder M, Rutten FH, McDonagh $T$, Mohacsi $P$, et al. Advanced Heart Failure Study Group of the HFA of the ESC. Palliative care in heart failure: a position statement from the palliative care workshop of the heart failure Association of the European Society of Cardiology. Eur J Heart Fail. 2009;11(5):433-43.

13. Alba AC, Agoritsas T, Jankowski M, Courvoisier D, Walter SD, Guyatt GH, et al. Risk prediction models for mortality in ambulatory patients with heart failure: a systematic review. Circ Heart Fail. 2013;6(5):881-9.

14. Schockmel M, Agrinier N, Jourdain P, Alla F, Eicher JC, Coulon P, Druelle J, Mulak G, Danchin N, Thilly N. Juillière $Y$; ODIN cohort participants. Socioeconomic factors and mortality in diastolic heart failure. Eur J Clin Investig. 2014;44(4):372-83.

15. Checa C, Abellana R, Verdú-Rotellar JM, Berenguera A, Domingo M, Calero E, et al. Social risk and mortality: a cohort study in patients with advanced heart failure. J Cardiovasc Nurs. 2019;34(1):E8-E15.

16. Moser DK, Robinson S, Biddle MJ, Pelter MM, Nesbitt TS, Southard J, et al. Health literacy predicts morbidity and mortality in rural patients with heart failure. J Card Fail. 2015;21(8):612-8.

17. Garcia R, Abellana R, Real J, Del Val JL, Verdú-Rotellar JM, Muñoz MA. Health inequalities in hospitalisation and mortality in patients diagnosed with heart failure in a universal healthcare coverage system. J Epidemiol Community Health. 2018:72(9):845-51.

18. Lynch S. Hospice and palliative care access issues in rural areas. Am J Hosp Palliat Care. 2013;30(2):172-7.

19. McMurray JJ, Adamopoulos S, Anker SD, Auricchio A, Böhm M, Dickstein K. ESC guidelines for the diagnosis and treatment of acute and chronic heart failure 2012: the task force for the diagnosis and treatment of acute and chronic heart failure 2012 of the European Society of Cardiology. Eur J Heart Fail. 2012;14(8):803-69.

20. Ramos R, Balló E, Marrugat J, Elosua R, Sala J, Grau M, et al. Validity for use in research on vascular diseases of the SIDIAP (information system for the development of research in primary care): the EMMA study. Rev Esp Cardiol (Engl Ed). 2012;65(1):29-37.

21. Formiga F, Chivite D, Casas S, Manito N, Pujol R. Functional assessment of elderly patients admitted for heart failure. Rev Esp Cardiol. 2006;59(7):740-2.

22. Charlson ME, Charlson RE, Peterson JC, Marinopoulos SS, Briggs WM, Hollenberg JP. The Charlson comorbidity index is adapted to predict costs of chronic disease in primary care patients. J Clin Epidemiol. 2008;61(12): 1234-40.

23. Domínguez-Berjón MF, Borrell C, Cano-Serral G, Esnaola S, Nolasco A, Pasarín Ml, et al. Constructing a deprivation index based on census data in large Spanish cities (the MEDEA project). Gac Sanit. 2008;22:179-87.

24. García González JV, Díaz Palacios E, Salamea García A, Cabrera González D, Menéndez Caicoya A, Fernández Sánchez A, et al. An evaluation of the feasibility and validity of a scale of social assessment of the elderly. Aten Primaria. 1999;23(7):434-40.

25. Domínguez Amorós M, Monllor Rico N, Simó Solsona M (2010). "Món rural i joves. Realitat juvenil i polítiques de joventut als municipis rurals de Catalunya". Col.lecció Estudis, 31. Generalitat de Catalunya.

26. Henning-Smith C, Moscovice I, Kozhimannil K. Differences in social isolation and its relationship to health by rurality. J Rural Health. 2019;35(4):540-9.

27. Buja A, Toffanin R, Rigon S, Lion C, Sandonà P, Carraro D, et al. What determines frequent attendance at out-of-hours primary care services? Eur J Pub Health. 2015:25(4):563-8.

28. Takiguchi M, Yoshihisa A, Miura S, et al. Impact of body mass index on mortality in heart failure patients. Eur J Clin Investig. 2014;44(12):1197-205. https://doi.org/10.1111/eci.12354.

29. Okabe T, Yakushiji T, Kido T, Oyama Y, Igawa W, Ono M, et al. Relationship between worsening renal function and long-term cardiovascular mortality in heart failure patients. Int J Cardiol. 2017;230:47-52

30. Vidán MT, Bueno $H$, Wang $Y$, Schreiner G, Ross JS, Chen J, et al. The relationship between systolic blood pressure on admission and mortality in older patients with heart failure. Eur J Heart Fail. 2010;12(2):148-55.

31. Timonin S, Kontsevaya A, McKee M, Leon DA. Reducing geographic inequalities in access times for acute treatment of myocardial infarction in a large country: the example of Russia. Int J Epidemiol. 2018;47(5):1594-602.

32. Neergaard MA, Brunoe AH, Skorstengaard MH, Nielsen MK. What socioeconomic factors determine place of death for people with life-limiting illness? A systematic review and appraisal of methodological rigour. Palliat Med. 2019:33(8):900-25.

33. Hawkins NM, Scholes S, Bajekal M, Love H, O'Flaherty M, Raine R, et al. Community care in England: reducing socioeconomic inequalities in heart failure. Circulation. 2012;126(9):1050-7.

34. Witte KK, Patel PA, Walker AMN, Schechter CB, Drozd M, Sengupta A, et al Socioeconomic deprivation and mode-specific outcomes in patients with chronic heart failure. Heart. 2018;104(12):993-8.

35. Muñoz MA, Mundet-Tuduri $X$, Real J, et al. Heart failure labelled patients with missing ejection fraction in primary care: prognosis and determinants. BMC Fam Pract. 2017:18(1):38.

\section{Publisher's Note}

Springer Nature remains neutral with regard to jurisdictional claims in published maps and institutional affiliations.
Ready to submit your research? Choose BMC and benefit from:

- fast, convenient online submission

- thorough peer review by experienced researchers in your field

- rapid publication on acceptance

- support for research data, including large and complex data types

- gold Open Access which fosters wider collaboration and increased citations

- maximum visibility for your research: over $100 \mathrm{M}$ website views per year

At BMC, research is always in progress.

Learn more biomedcentral.com/submissions 